International Journal of Linguistics, Literature and Culture
Available online at https://sloap.org/journals/index.php/ijllc/
Vol. 7, No. 4, July 2021, pages: 236-240
ISSN: 2455-8028
https://doi.org/10.21744/ijllc.v7n4.1766

\title{
Paraphrases Related To the Language of Advertising
}

Shakhnoza Mukhamedumarovna Yunusova ${ }^{\text {a }}$

Article history:

Submitted: 9 March 2021

Revised: 18 April 2021

Accepted: 14 May 2021

\section{Keywords:}

advertisement language;

advertisement text;

ktematonym;

paraphrase;

slogan;

verbal text;

\begin{abstract}
The article deals with the language of advertising in Uzbek Language. The objective of the work is to provide the analysis of language of advertising from linguistic point of view and specify linguistic means used in advertising texts. The format of the advertising text is a certain difference compared to other functional properties of the text style. This is one of the distinguishing features mentioned are used in the title of any kind of short news reports in newspapers. The title of the advertising is important to the composition of the advertising creation relevant information. It's the most important and interesting part of the target audience to attract attention. Text title, in general, does not explain all the details. We have the scientific language of the advertising text in a statement issued through the media; we will focus on the style characteristics of scientific and scholarly texts.
\end{abstract}

International journal of linguistics, literature and culture (C) 2021. This is an open access article under the CC BY-NC-ND license (https://creativecommons.org/licenses/by-nc-nd/4.0/).

\section{Corresponding author:}

Yunusova, S.M.

Senior Teacher,

Tashkent State Pedagogical University named after Nizami, Tashkent, Uzbekistan

Email address: shakhnozayunusova@mail.ru

\footnotetext{
a Tashkent State Pedagogical University named after Nizami, Tashkent, Uzbekistan
} 


\section{Introduction}

Nowadays, advertising is not only a means of promoting the product, but also a rapid factor that demonstrates certain achievements in production, informs the population, has a rapid impact on the mental and intellectual state of man, reflects the potential of our native language. From the point of view of this period, the social value of advertising, the expression of opinions on linguistic research is one of the current topics.

Thanks to independence, Uzbekistan has become the owner of its national wealth. He chose his path in economic development and began to create a system of production in line with national interests. Uzbekistan has become an independent and equal member of international economic relations. He set out to address the challenges of transitioning to a market economy and ensuring economic independence through advertising and reform.

At a time when the Republic of Uzbekistan is facing the world, the need and attention to the development of relations with foreign countries and the development of the economy, the skills of advertising Uzbek goods is growing day by day. In the process of transition to a market economy, the focus on advertising on the formation of marketing is naturally increasing. Advertising of products, imported goods and other services of various firms, companies, enterprises and organizations is also widely used in the media.

\section{Main Findings and Results}

Uzbek advertising is a rapidly evolving modern process, characterized by its own rules and peculiarities as an industry. Research in this area shows that advertising is not only a force that drives sales, but also a force (stimulus) that adapts speech activity to the demands of the time, increasing its impact.

According to Macken Erickson Incorporated, "Advertising is a well-told truth at the time" (In the media..., p. 4). Advertising affects not only the consumer market, but also the political and cultural life of society, as well as the development of our language. Nowadays, there is a great need for advertising messages, as a result of which certain types and forms of advertising text appear and are emerging. Compare: announcement, announcement, annotation, poster, etc.

A peculiar, important feature of the text of advertisements is that in the same process a small amount of information through a small number of linguistic units - words, phrases - message, information. The informative text can be divided into the following parts.

- Ktematonym (gr. ktemo "property" + onima "name") - a verbal expression of a trademark;

- Slogan (visual slogan "slogan") - a short slogan representing brand advertising. It should be concise, clear and easy to remember;

- The function of a ktematonym or advertised product in society is to express the idea - the content in a concise and descriptive form. This process can be conveyed in one or two sentences (Stylistics and literary editing, 2004: 158).

A natural question arises. What should ad texts look like?

- Advertising text should be clear and purposeful. In other words, the main, important message should be as a slogan. Compare: breakfast in 5 minutes. Slake - life is on the move;

- Advertising text must be valid, logically consistent and understandable;

- Advertising text should be exact, short, and concise;

- The ad text should be methodologically popular;

- Advertising text must be original. It should also be interesting and fun.

Advertising is a process that everyone can face every day, everywhere. Advertising is penetrating all areas of mass communication. Based on the media, advertising can be divided into the five most important types. These are:

- Press advertising;

- Radio advertising;

Yunusova, S. M. (2021). Paraphrases related to the language of advertising. International Journal of Linguistics, Literature and Culture, 7(4), 236-240. https://doi.org/10.21744/ijllc.v7n4.1766 
- Television advertising;

- Outdoor advertising;

- Internet advertising, etc.

Advertising serves a number of functions in society. Important:

- Advertising should provide information;

- Advertising should be convincing (Farby, 2004).

The function of advertising text is to sell a product, not just sell it, but also promote and promote it. In advertising, the term "sell" means to persuade the reader to buy, to "vote for the product". The ad text is one of the most valuable texts in the world and they pay good money for its publication. Because advertising - the sale of goods begins through the advertising text, and the intensive sale of goods brings the owner of the goods wax money, income. Income, on the other hand, further expands trade in goods, creating opportunities for large-scale trade, especially to increase the value of goods. Consequently, the whole process begins, first of all, with advertising - the power of the impact of the advertising text, the power of attracting the public - buyers. Accordingly, the ad text is one of the most valuable texts and they pay good money for its publication.

It turned out that every word in advertising is subject not only to artistic information requirements, but also to the most important high economic requirements, and each word serves for trade. This is a requirement of a market economy (Rasulov, 2006). Advertising language is the expression of the content of advertising text using the visual means of language (Kaplan, 2020). The specific content, the expression of the idea through the advertising text is clear. This is a fact that does not require proof. However, the fact is that this "idea" of advertising is characterized by its own stylistic color, its own connotation, as well as its own phonetic accent and tone. The language of advertising text - text units, elements of which are arranged in a certain order in the process of expression, conveying information about the intended event, event, thing, object, language and speech units with different structures serve to convey this message to the listener. That is, in the structure of the advertising text, a word, a phrase or a sentence is involved.

If the text is generally viewed as a complete whole with independent content and formalized by language, then the advertising text is defined by a mature language form that is short but fully reveals the advertising idea, main idea and content. It is important to form an advertising image in the advertising text using various lexical, syntactic and pictorial means. The advertising image creates a clear picture of the subject and creates certain emotions that affect the consumer. The words that the advertiser chooses to create verbal texts should draw attention to themselves and be remembered quickly (Imshinetskaya, 2004; Thompson et al., 2008; Gardner \& Luchtenberg, 2000). Advertising text is the sum of advertising content and its form of expression, i.e. a set of ideas and expressions.

\section{Results and Discussions}

The characteristics of advertising activities require careful selection of language tools, taking into account the goals and objectives of advertising impact. Tropes such as metaphor, metonymy, hyperbole, paraphrase, allegory, imitation can be cited as means of vocabulary activation (Rosenthal, 1981), (Kalinina, 2015).

Paraphrases are one of the most influential, important tools widely used in advertising language. Paraphrases are descriptive means and serve as a specific method-descriptive method in speech. In other words, paraphrases are things, not events in their own name, but a descriptive way of expressing them on the basis of their characteristic features; such an expression. For example, the queen of the field (corn), like the blue flame (gas) (Hojiev, 2002; Byun \& Jang, 2015; Wyer Jr, 2002).

Paraphrases, as a stylistic tool, give the speech an uplifting, figurative, enrich the vocabulary based on the requirements of social development (Rasulov, 1997; Bruthiaux, 2000; Flores et al., 2014). Hence, paraphrases are one of the methodological tools that show the richness of our language.

Paraphrases also have a certain figurative expression in the language of advertising. Paraphrases are common in the language of advertising, especially in the advertising of soft drinks. The following paraphrases in Kavsar mineral water advertising provide specific message, information, understanding, and serve for connotative information. Compare: 
- Kawsar is a beauty-sharing;

- Kawsar - the taste of heaven.

In dictionaries, the word kawsar is interpreted as follows: 1. According to Islamic belief, the name of the pool in paradise; 2. Clean, cold, clear (about water). There is a logical connection in both interpretations, and they form a whole. That is, a pool-water-filled, water-filled, water-storage circle-shaped depth, land. So, a person who drinks kawsar water in the paraphrase of the beauty-sharing will enjoy this beauty. The paraphrase of the heavenly flavor, on the other hand, expresses the sweetest, sweetest, tastiest, coldest, clearest meanings of kavsar mineral water, just like the pool water of heaven.

Omonkhona - healing water.

In the paraphrase of the healing water, it is reported that the spring water flowed naturally from the territory of Omonkhana. That is, it is thought that this water has healing, healing properties, that a person should be cured of this water and consumes it.

Aqualite is family-strengthening water.

In the family-strengthening water paraphrase, it is reported that the water under the Aqualight brand will be placed on the holiday table and will help the family gather around the table, making the family stronger.

Hydrolife is the water that shakes the cradle of mountains.

In the paraphrase of the water that shakes the cradle of the mountains, the natural purity flowing from the ground of the Mingbulak mountain range. Hydrolife mineral water is reported to be mountain water, rock-hard, and ripening an environmentally friendly, natural liquid.

Arctic - feel the temperature of the glaciers.

In the paraphrase of feel the temperature of the glaciers, it is reported that on hot days, this water has a cold effect on the human body, soothes the soul, quenches thirst and reduces body temperature.

\title{
4 Conclusion
}

Hence, paraphrases related to the language of advertising are directly related to cool drinks, giving a figurative, figurative message about the properties of these drinks, such as thirst quenching, taste, naturalness, and healing, mineral richness. It calls for the same drinks to attract the attention of the consumer market - consumers, consumers to buy, consumers to buy, consumers to consume, and so on. So, the language of advertising is not an abstract consumer language, the language of business, but a kind of live communication with the public - the language of advertising communication.

\section{Conflict of interest statement}

The author declared that (s)he has no competing interest.

\section{Statement of authorship}

The author has a responsibility for the conception and design of the study. The author has approved the final article.

\section{Acknowledgments}

I am grateful to two anonymous reviewers for their valuable comments on the earlier version of this paper.

\author{
Yunusova, S. M. (2021). Paraphrases related to the language of advertising. International \\ Journal of Linguistics, Literature and Culture, 7(4), 236-240. \\ https://doi.org/10.21744/ijllc.v7n4.1766
}




\section{References}

Bruthiaux, P. (2000). In a nutshell: persuasion in the spatially constrained language of advertising. Language \& Communication, 20(4), 297-310. https://doi.org/10.1016/S0271-5309(00)00003-3

Byun, J., \& Jang, S. S. (2015). Effective destination advertising: Matching effect between advertising language and destination type. Tourism Management, 50, 31-40. https://doi.org/10.1016/j.tourman.2015.01.005

Farby E.D. (2004). How to create a successful advertisement. - Saint Petersburg.

Flores, W., Chen, J. C. V., \& Ross, W. H. (2014). The effect of variations in banner ad, type of product, website context, and language of advertising on Internet users' attitudes. Computers in Human Behavior, 31, 37-47. https://doi.org/10.1016/j.chb.2013.10.006

Gardner, R., \& Luchtenberg, S. (2000). Reference, image, text in German and Australian advertising posters. Journal of pragmatics, 32(12), 1807-1821. https://doi.org/10.1016/S0378-2166(99)00117-4

Hojiev, A. Annotated Dictionary of Linguistic Terms. 2002. Tashkent: “UzME” publishing house, 136.

Imshinetskaya I. (2004). Creative in advertising: - Moscow: RIP - Holding.

In the media: advertising theory and practice. (2000) Text of lectures. - Tashkent: National University of Uzbekistan. 2000.

Kalinina, I. M. (2015) Linguistic aspect of the advertising text. I. M. Kalinina, E. V. Kovalenko. Young scientist. No. $10.5(90.5)$

Kaplan V.A., Nikitina V.S., Sakhno A.S. [and others].The language of advertising. Young scientist. 2020. No. 5 (35).

Rasulov R. and others. (2006). Paraphrases related to the language of advertising. Pedagogical education, 3.

Rasulov R., Umirov I. (1997). Annotated dictionary of figurative expressions of the Uzbek language. - Tashkent.

Rosenthal D.E. (1981). Language of advertising texts: Textbook. D.E. Rosenthal, N.N. Kokhteev. - Moscow.

Stylistics and literary editing. (2004) Under the editorship of Prof. V.I. Maksimov. - Moscow: 2004.

Thompson, D. A., Flores, G., Ebel, B. E., \& Christakis, D. A. (2008). Comida en venta: after-school advertising on Spanish-language television in the United States. The Journal of pediatrics, 152(4), 576-581. https://doi.org/10.1016/j.jpeds.2007.09.011

Wyer Jr, R. S. (2002). Language and advertising effectiveness: Mediating influences of comprehension and cognitive elaboration. Psychology \& marketing, 19(7-8), 693-712. https://doi.org/10.1002/mar.10031 